\title{
Shared Experiences of Filipino Immigrant Workers in Acquiring Nihongo
}

\author{
Arriane Mae D. Lingo ${ }^{1}$, Marivel D. Lisbos ${ }^{2}$, Alma Mae G. Yoshida ${ }^{3}$ \\ Bachelor of Arts in English, UM - Matina Campus, Davao City, Philippines \\ larrianemaelingo@yahoo.com, ${ }^{2}$ lisbos_marivel@yahoo.com, ${ }^{3}$ may591130@gmail.com
}

Dr. Mary Ann E. Tarusan, EdD, PhD

Language Professor, UM - Matina Campus, Davao City, Philippines

\begin{abstract}
This study aimed to explore the shared experiences of Filipino immigrant workers in acquiring Nihongo; their acquisition strategies, the language experiences and the insights gained in the acquisition process. The method used is qualitative multiple case study. The tool used in gathering the essential information for this study is the in-depth interview. The participants of this study are four Filipino immigrant workers in Japan. The results revealed that the participants acquired Nihongo through employing various strategies that helped them improve communication skills, which was beneficial to their profession. Apparently, the participants encountered various language experiences but were primarily beneficial for their part. The participants met various difficulties in the acquisition process such as using language honorifics, proper stressing for correct pronunciation of words and language attrition, but through these challenges the participants realized the importance of interest and willingness to succeed in acquiring a new language.
\end{abstract}

Keywords: Filipino immigrant workers, Acquisition of Nihongo, University of Mindanao, Acquisition Strategies, Language Experiences.

\section{INTRODUCTION}

Language is essentially human. Gibson (2013) purported that language is an effective tool for communication to form bonds. Relationships are stalwartly built among people, groups, and nations through effective communication. Moreover, it yields an understanding among individuals predominantly, those who are at work that brings greater satisfaction and later on constitutes peace and harmony. Accordingly, in today's business dominated society, the ability to speak a foreign language can be an advantage and might subsequently give everyone an edge when in search for a job or maintaining a job. Pennington (2014) supported that people must urge themselves to learn a second language in order to enter a combative world, a new language skills does not only provide the learner the ability to communicate, but also to widen their understanding of the world. Filipino immigrant workers around the globe were fervent to be fluent in speaking the language of whatever host country they are assigned to for the reason of wanting to be able to communicate and hence, do their consigned occupations in the most effective way. In addition, Filipino immigrant workers who have been successfully employed in a country where only native language is spoken (i.e. Japan), gained more enthusiasm and willingness to learn the language (i.e. Japanese language) for the reason that native speaker expresses appreciation in return to the evident effort exerted by the foreigner through having knowledge not just about their tradition and culture but also becoming more familiar about their language.

This study focused on the shared experiences of immigrant workers in acquiring a second language particularly Filipino workers in Japan. The study explored the strategies that the immigrant workers employed in acquiring the Japanese language, the language experiences they encountered as well as the insights they gained in the acquisition process.

\subsection{Statement of the Problem}

In order to discover themes that would lead the researchers to gain information on the shared experiences that the immigrant workers encountered in their acquisition of the Japanese language. The following questions were formulated: 
1. How did the immigrant workers acquire Nihongo?

2. What are the language experiences of the participants in acquiring Nihongo?

3. What are their insights in acquiring Nihongo?

\subsection{Theoretical Lens}

This study was anchored on the theory of Second Language Acquisition by Stephen Krashen, (1987). This theory contends that language acquisition does not necessitate extensive use of conscious grammatical rules, and does not need tedious drill. Acquisition requires meaningful interaction in the target language - natural communication - in which speakers are primarily concerned with the messages they are conveying and understanding, not with the form of their utterances.

\section{METHOD}

The method of this study utilized multiple case study.

\subsection{Research Design}

This study used a qualitative research design in order to explore the shared experiences of the Filipino immigrant workers in acquiring Nihongo. Johnson and Onwuegbuzie (2004) stated that qualitative research method is used when little is known about a topic or phenomenon and when one wants to know or learn more about it and is commonly used to understand people's experiences and to express their perspectives. San Jose (2012) averred that qualitative method is more dynamic than the structured format of the quantitative method.

This present study made use of the qualitative-multiple case study method. This method is considered appropriate for this study because it explores the various experiences of the participants in their quest in acquiring Nihongo. Accordingly, a qualitative method is appropriate to utilize in order to substantially attain knowledge on the different experiences of Filipino immigrant workers in their acquisition of the Japanese language.

Willis (2007) observed that a case study research design allows one to gather rich, detailed data in an authentic setting. It is holistic and supports the idea that much of what we know about human behavior is best understood as lived experiences in the social context. Merriam (2009) contended that a case study explores into case by means of in-depth information collection, which involves multiple sources.

\subsection{Research Participants}

This study explored the shared experiences of the participants in their acquisition of the Japanese language, the strategies they employed, the pleasant and unpleasant experiences they encountered as well as the insights they gained in the acquisition process. Furthermore, this study focused on the Filipino immigrant workers in Tokyo, Japan. The ages of the Filipino immigrant participant ranged from 30 years old to 40 years old. They migrated to Japan for at least ten years. The participants left for Japan without undergoing formal education of the Japanese language. These four immigrant participants are all currently residing in Japan and acquired the Japanese language as a tool for their survival. They had been residing in Japan for more than ten years from the time this study was conducted.

\subsection{Research Instrument}

In-depth interview has been used as the data-gathering tool in this research. Bless and Higson-Smith (1995) stated that in-depth face-to-face interviews involve direct contact with the participant who is asked to answer questions, providing participants the opportunity to comment on widely defined issues. Moreover, the construction of the interview guide questions is in line with the research questions of the study. It concentrated on shared acquisition experiences of the participants. It includes the strategies used in acquiring the Japanese language, various experiences and the insights they gained in the acquisition of the target language. The interview guide questions were created to serve as a guide for the conversation with the participants with the aim of drawing out information pertaining to the Japanese language acquisition process. 


\subsection{Data Gathering}

The researchers informed the participants of this study, its purpose and that their help was very essential in the fulfilment of the aim of this study by video calling them using face time and the researchers received a positive response of willingness to partake in the study. For ethical reasons, we sent letters through e-mail to formally inform them of the purpose of our study together with the consent letters confirming their upcoming engagement in this study.

The study conducted separate interviews to each participant in respect of their privacy. An in-depth interview was conducted with the participants to be able to collect privileged information of their experiences in acquiring the Japanese language.

One of the researchers went to Tokyo to personally conduct the first interview because we believe that by doing so the participants would be more relaxed in sharing the details of their experiences face to face with the interviewee and it is easier to pitch probe questions in a natural atmosphere.

On the initial interview, the researcher explained to the participants the purpose of the interview, the aim of the study and that the interview would be recorded using an IC recorder. The participants were also informed that follow-up interviews would be conducted but through the use of technology such as skype or face time and that also these interviews were recorded for the sole used of the purpose of this study. The interview guide questions were asked followed by probe questions to obtain deeper information of the subject.

Preceding the interview, the interviewee explained the main purpose of the study. Then, the interviewee conducted the in-depth interview utilizing interview guide questions and followed the interview protocol to ensure the smooth run of the interview. In addition, the researchers handed the participants the consent letter for them to affix their signature. On the session of the interview, the interviewee maintained a comfortable environment. The researchers expressed their deepest gratitude to the participants for cooperating in the study.

\subsection{Trustworthiness}

Trustworthiness establishes the validity and reliability of qualitative research. Streubert, Speziale and Carpenter (2003) described trustworthiness as "establishing the validity and reliability of qualitative research". Additionally, Talbot (1995) stated that a qualitative research is trustworthy when it accurately represents the experiences of the study participants. In this study, the researchers made sure that the analysis of the findings of the information were supervised by the data analyst and all the information gathered were honestly verified by the research participants. Prior to the interview, the researchers asked permission from the study participants, for them to be informed of the purpose of the study.

Guba (1981) believed and recommended these four criteria that needs to be considered in the aim of creating a trustworthy study: credibility, transferability, dependability, confirmability.

Credibility in a qualitative research is the level to which the data gathered and data analyses are authentic and trustworthy. Credibility is an evaluation of whether or not the research findings represent a "credible" conceptual interpretation of the data drawn from the participants' original data (Lincoln \& Guba, 1985). Credibility was concretized in this study by making sure that the recorded and transcribed interview were presented to the participants for verification. After all the interviews has been transcribed, researchers sent emails to communicate to the participants to have them validate everything.

On the other hand, Trochim (2000) referred transferability to as the degree to which the results of qualitative research can be generalized or transferred to other conditions or scenes. Furthermore, Streubert, Speziale \& Carpenter (2003) stated that transferability is also called "fittingness" for it determines whether the findings suit in or are transferable to similar situations. Moreover, Lincoln \& Guba (1985) used transferability as a term that implies generalizability of the findings and results of the study to other settings, situations, populations and circumstances. Transferability was obtained in this study by presenting detailed information of the setting and other information about the participants of the study discussed in the research participants section of the study.

Lincoln \& Guba (1985) defined dependability as the evaluation of the quality of the integrated processes of data collection, data analysis, and theory generation. Thomas \& Magilvy (2011) asserted 
that the dependability of a study is high if another researcher can readily follow the series of decisions used by the initial researcher. It gives emphasis on the consistency of the outcome of the research. To deal this issue of dependability, the research questions of this study were authenticated and confirmed by experts and the participants verified the transcribed in-depth interviews.

Confirmability refers to the degree to which the results could be confirmed or supported by others. Trochim (2000) averred that to enhance the conformability of the study the researcher should document the procedures for checking and rechecking the information in the duration the study. To prove the confirmabilty of this study, the researchers provided an audit trail. Shenton (2004) contended that an audit trail allows any observer to trace the course of the research step-by-step via the decisions made and procedures described. San Jose (2012) added that, the audit trail serves as a reference index for the transcripts of the interviews.

\subsection{Scope and Limitation}

This study was conducted accompanied by its scope and limitations to show emphasis on a certain topic and to show a clear scope. The focus of this study is the participants shared experiences in acquiring the Japanese language. In order to achieve this aim, the researchers explored the strategies that the immigrant workers employed in acquiring the Japanese language, the language experiences they encountered as well as the insights they gained in the acquisition process.

Furthermore, there are four (4) Filipino immigrants who participated in this study which age ranged from 30 to 45 years old. Creswell (2007) averred that four or five cases are adequate enough in discovering themes of the subject and is enough to perform a cross-case subject examination. Yin (2003) asserted that having more than two cases would generate more effective results.

On the other hand, the research only delimits to Filipino immigrant workers who migrated to Japan for at least ten years. Since the study aims to explore the shared various experiences of the immigrant workers in acquiring Nihongo the researchers only included Filipino immigrant workers who has at least migrated to Japan for ten years. In addition, the study only used qualitative multiple case study as the research design and pertaining to the gathering of information from the participants, an in-depth interview was utilized equipped with an IC recorder. Furthermore, the analysis of the data gathered was only limited to qualitative type in which only the participants' experiences during the Japanese language acquisition process; their acquisition strategies, their various experiences and the insights the gained in the process.

\section{RESUltS AND DisCUSSION}

\subsection{Results}

\subsubsection{Acquisition of the Japanese Language}

The study found out that the Filipino immigrant workers had been constantly exposed to the target language at their workplace and that they employed various strategies in acquiring the Japanese language, such as listening to conversations and jotting down words. In addition, they also consulted the dictionary as well as asking their co-workers for clarifications. They constantly practice by using newly learned words in interacting with native speakers. In contrast, Participant B added another strategy through listening while reading the lyrics of the Japanese songs played at her workplace. She added that these strategies helped her learn the proper pronunciation and improving her communication skills giving her confidence in interacting with native speakers. In addition, Participant D mentioned that she watched Japanese television programs. All of the participants asserted that the strategies they employed were practically useful in the improvement of their communication skills, which was favorable to their work.

\subsubsection{Language Experiences}

The participants encountered various language experiences in their interaction with the native speakers and with their co-Filipino immigrant workers. Most of them were pleasant experiences except for the case of Participant D. She got prank by her Filipino co-worker and was asked to utter a foul word, which sounded like a word from her first language, in front of many native speakers. On the brighter side, Participant $D$ felt overwhelmed on the appreciation she received from the native speakers in becoming fluent of their language while Participant B gained respect from the native speakers and gained the ability to do transactions independently. Participant $\mathrm{C}$ felt more determined to learn more of the target language after becoming competent in communicating. 
Simultaneously, the participants divulged that they were exposed to the target language everyday and that they use a combination of Philippine languages and Japanese language in private conversations with their co-Filipino immigrant workers. Participants B, C, D denied using the same strategies in speaking the Japanese language in other situations, as there was no such opportunity for them to be able to do so. Differing to them, Participant A shared that she used the same strategies in speaking the Japanese language in learning the English language.

\subsubsection{Insights in Acquiring Nihongo}

The study showed that all the participants experienced a decline in the vocabulary of their first language and that they found it difficult in expressing their thoughts using only their first language and that the first language comes out their mind is the Japanese language. Additionally, Participant C found the use of verb tenses challenging. Participants A and C claimed that they had difficulties in the proper pronunciation of the Japanese words. Participant B encountered difficulty in choosing the appropriate words to be used in conversing according to the listener's age, rank and social status. Participant $\mathrm{D}$ found it hard understanding various dialects of the target language and she also realized the importance of interest and willingness to successfully acquire a language. In addition, she noticed that the manner of the utterances of the men and women were different even if they both meant the same thing. On the lighter side, Participant A shared that after acquiring the target language she gained awareness of what is happening around her. Participant $\mathrm{C}$ said that she became interested to learn to write Japanese after attaining fluency on the language.

\subsection{Discussion}

\subsubsection{Acquisition of Nihongo}

Ellis (1997) defines second language acquisition as the way in which people learn a language other than their mother tongue either inside or outside of a classroom. In addition, second language acquisition is the learning of a nonnative language in the environment in which that target language is spoken (Gass \& Selinker, 2008).

In line with the statement above, the study showed that the participants acquired the Japanese language through everyday exposure to the target language and by employing various acquisition strategies. Ellis (1997) averred that successful learners use more strategies compared to unsuccessful learners and that these strategies may involve formal practice (i.e. rehearsing a new word) that would contribute to the development of linguistic competence while strategies involving functional practice (i.e. seeking out native speakers to talk to) aid the development of communicative skills. For instance, all four participants listened to conversations jotted down words, consulted the dictionary, asked their co-workers and was coached by them and immediately used their newly learned words in interacting with native speakers. Taylor's Authentic language input (1994) stated that movies, singing shows, stories, games and plays are important authentic materials contributing to the development of acquiring a language for they comprise the characteristics of language used by the native speakers. In line with this, Participant D had an additional strategy she watched Japanese television programs. As for Participant B, she acquired the language by listening and reading the lyrics of Japanese songs played at her workplace. In addition, Participant $\mathrm{C}$ stated that she gained confidence in interacting with native speakers. Moreover, the participants employing all the strategies learned the proper pronunciation of words and improved their communication skills.

Ellis (1994) contends that language-learning strategy consists of a mental or behavioral activity related to some specific stage in the overall process of language acquisition or language use. Different kinds of learning strategies have been identified. Cognitive strategies are those that are associated in the analysis, synthesis, or transformation of learning materials. 'Recombination' involves constructing a meaningful sentence recombining known components in second language in a new way. Metacognitive strategies are those concerned with planning, monitoring, and evaluating learning. 'Selective attention' is where the learner makes a conscious decision to attend to particular aspects of the input, Social or affective strategies is associated in the ways in which learners choose to interact with other speakers.' Questioning for clarification' it is asking for repetition, a paraphrase or an example. Studies attempting to discover which strategies are important for second language acquisition found out that successful language learners pay attention to both form and meaning (Ellis, 1997). 


\subsubsection{Language Experiences in Acquiring the Japanese Language}

Japan is ethnically, culturally and linguistically a homogeneous country (Miller, 1980). Wherein, 99 percent of its population speaks Japanese as their first language. As shown in the latest statistics in Ethnologue, Japanese is the most popular language on the island.

Krashen (1985) averred that conversations with sympathetic native speakers who are willing to help the acquirer understand are very helpful. The experiences of the participants in the acquisition of the Japanese language were a variety of good and bad experiences. These experiences were mostly encountered at their workplace. All of these experiences are products of their interactions with coFilipino workers and Japanese native speakers. In Long's Interaction Hypothesis (1996), an important aspect in developing second language acquisition is conversational interaction wherein the arbitration of meaning causes interactional alterations by the native speakers or more proficient speaker in social interaction. Additionally, the participants were advised to use the Japanese language at their workplace. Thus, giving them the chance to practice and enhance their Japanese language fluency. In contrast, the participants used a mixture of Philippine languages and the Japanese language in private conversations with co-Filipino workers. Most of the participants' experiences were good. All of them contended that their co-workers who were already fluent at the target language taught them patiently. Participant A shared that her co-worker taught her how to read Kanji, that lead to her realization that a single Kanji may have many meanings depending on its use. Participant B added that because of her acquisition of the Japanese language she was able to do daily transactions independently and gained respect from native speakers. On the same matter, Participant D divulged that she felt overwhelmed by the appreciation that she received from native speakers, which opposed the feeling that she felt when her Filipino co-worker pranked her. Resultative motivation as explicated by Ellis (1997) is the motivation that came from a successful experience in learning a language. Evident in the case of Participant $\mathrm{C}$, she stated that felt more determined to learn more of the target language after becoming fluent in speaking the language.

\subsubsection{Insights in Acquiring the Japanese Language}

Language attrition as defined by Yukawa (1997) is a permanent or temporary regression from a speaker's previous linguistic performance or competence at any linguistic level exerting any linguistic skill. Schmid (2011) stated that first attrition is highly noticeable in speakers who have migrated to another country and subsequently lived in a second language dominant environment. First language attrition has been evident in the cases of the four participants. The four participants shared the same contention that the more they acquired the Japanese language led them to forgetting their first language. Thus, making it difficult for them to express their thoughts using only their first language. They also added that Japanese words come out first on their minds before any other language. Moreover, Participants A \& C both agreed that proper enunciation of words is necessary to avoid miscommunication because different pronunciation of the word leads to a change in its meaning. Miyagawa (1999) clarified that unlike English language that has stress accent, Japanese has pitch accent, which means that after an accented syllable, the pitch falls. The word for "chopsticks," hashi, has the accent on the first syllable, so its pitch contour is ha shi. Without the accent on the first syllable, hashi may mean "bridge" or "edge". Participant D shared that she noticed that the language of the male and female have differences. The women's language was always proper and polite while men spoke in a masculine manner, although they both meant the same. In addition, she divulged that she had difficulty grasping the meaning of the native speaker's utterance because they talk fast and also had a hard time understanding different variation of dialects and says it is incomprehensible but later on realized the importance of interest and willingness to learn the language to successfully acquire a new language. Krashen (1985) contends that attitudes can act as barriers or bridges to learning a new language and are the essential environmental ingredient for language acquisition. Learning can only happen if certain affective conditions, such as positive attitudes, self-confidence, low anxiety exist and that when these conditions are present input can pass through the affective filter and be used by the learner. Participant $C$ shared that her difficulty was the use of the tenses of the verb but after overcoming acquisition difficulties she became interested in learning to write Japanese. Richards and Schimdt (2002) asserted that motivation is generally considered to be one of the main causes of success and failure in second language learning. Participant A gladly averred that after successfully acquiring the target language, she gained awareness of the things that has been happening around her. On the other hand, Participant B divulged that choosing words and using the appropriate 
language according to the listener's age, rank and social status was very challenging. The Japanese language employs an immense system of politeness and honorific markers. It is often the case that in order to utter any kind of expression, the speaker must keep in mind his or her social standing to the person addressed, and the person being talked about (Miyagawa, 1999).

\section{CONCLuSion}

The results showed that the Filipino immigrant workers employed various strategies in acquiring the Japanese language and these strategies have deemed to be practically helpful in their acquisition of the target language thus giving them advantages in their jobs. Some shared common strategies and some had employed additional strategies. Furthermore, the results showed that motivation plays a vital role in acquiring a language. The participants possessed instrumental motivation as they acquired the language to be able to converse with their native speaker clients as well as integrative motivation for them to be able to socialize and function in their new community.

The participants had various language experiences but most of their cases showed positive results in the language acquisition process.

All the four participants shared the same sentiment that the more they acquired the second language resulted to a decline in the vocabulary of their first language, and the first word that comes on their minds is the Japanese language which gives them difficulty in expressing their thoughts using only their first language. However, the acquisition of the target language has been favorable to them, in terms of giving them motivation to learn more of the language thus giving them awareness of the things happening around them and giving them the capability and confidence to interact and transact with native speakers providing them great advantage in their work. The acquisition experience made them realize the importance of interest and willingness in acquiring a new language despite encountering difficulties in understanding various dialects, using verb tenses and proper enunciation of the target language as well as identifying appropriate words to be used according to the listener's age, position and social status.

\subsection{Implication for Practice}

Through this study the researchers found out that the Filipino immigrant workers employed various strategies in acquiring the Japanese language. After successfully acquiring the target language the participants gained confidence in interacting and establishing good rapport with the native speakers. In addition, if there is interaction there is an exchange of information and having common knowledge within the community gives a sense of belongingness to an outsider thus giving that individual self esteem making him a productive and effective member of the new community.

Furthermore, the study shows that the participants encountered various difficulties in acquiring a second language and to be able to triumph over obstacles one must possess willingness and interest in learning the language. Their motivation was vital in surpassing the challenges in acquiring the target language, which became their strength in living in a foreign country.

Moreover, acquisition of a second language gives an edge to an individual in this globally competitive generation in terms of higher chances of employment and becoming a tool for establishing intercultural communication. An immigrant skilled with communicative competence of the host country's language has a wide range of occupation choices as well as employment opportunities.

This study will be useful for future second language teachers enlightening them of the strategies that may be employed in their teaching profession giving them awareness of the importance of motivation and acknowledging that learners have learning preferences.

\section{REFERENCES}

Bless, C., \& Higson-Smith,Q. (1995). Fundamentals of social research methods: An african perspective. Cape Town. Creda Press.

Creswell, J.W. (2007). Qualitative inquiry and research design: Choosing among five approaches. $\left(2^{\text {nd }}\right.$ edition). Thousand Oaks, CA: Sage.

Ellis, R. (1994). The study of second language acquisition. Oxford: Oxford University Press.

Ellis, R. (1997). Second language acquisition. Oxford University Press. 
Gass, S., \& Selinker, L. (2008). Second language acquisition: An introductory course.(3 ${ }^{\text {rd }}$ edition). Taylor and Francis.

Gibson, M.J. (2013). Language as Bridge Builder. Retrieved from http://www.sinsinawa.org/site_ map/dvmay2013/bridge_builder.html

Guba, E.G. (1981). Criteria for assessing the trustworthiness of naturalistic inquiries. Educational Communication and Technology Journal 29, 75-91.

Johnson, R. B., \& Onwuegbuzie, A. J. (2004). Mixed methods research: A research paradigm whose time has come. Educational Researcher, 33(7), 14-26.

Krashen, S. (1985). The input hypothesis. Torrance, CA: Laredo Publishing Company.

Krashen , S.D. (1987). Principles and practice in second language acquisition. Prentice-Hall International.

Lincoln S. Y., Guba E. G.(1985). Naturalistic inquiry. Thousand Oaks, CA: Sage.

Long, M. (1996). Interaction Hypothesis. Retrieved July 8, 2015. From http://slaencyclopediaf10. wikispaces.com/Interactional+Hypothesis+\%28Michael+Long\%29

Merriam, S. (2009). Qualitative research: A guide to design and implementation. San Francisco, CA: Jossey-Bass.

Miller, R.A.( 1980). Origins of the Japanese language. University of Washington Press.

Miyagawa, S. (1999). The Japanese Language. Retrieved July 5, 2015, from http://web.mit.edu/jpnet/ articles/JapaneseLanguage.html

Pennington, R. (2014, April 21). Globalization And Language Learning - Framing the Global. Retrieved May 21, 2015, from http://framing.indiana.edu/2014/04/21/globalization-languagelearning/

Richards, J.C., Schmidt, R. (2002). Longman dictionary of language teaching and applied linguistics. ( $3^{\text {rd }}$ edition). Edinburgh: Pearson Education Ltd.

San Jose , A.E. (2012). Linguistic Experiences of Adult Dyslexic Learners.UIC Research Journals, 18 (1).

Schmid, M. S. (2011) Language attrition.NewYork:Cambridge University Press.

Shenton, A. (2004). Strategies for Ensuring Trustworthiness in Qualitative Research Projects. Retrieved January 13, 2015, from http://www.crec.co.uk/docs/Trustworthypaper.pdf

Streubert, Speziale and Carpenter Block, D. (2006). The social turn in second language acquisition. Edinburgh: Edinburgh University Press.

Talbot, L.A. (1995). Principles and practice of nursing research.St. Louis, MO: Mosby-Year Book.

Taylor, D. (1994). Inauthentic authenticity or authentic in authenticity? Teaching English as a Second or Foreign Language 1, 1-10.

Thomas, E., Magilvy, J. K. (2011). Qualitative rigour or research validity in qualitative research. Journal for Specialists in Pediatric Nursing, 16, 151-155.

Trochim, W. (2000). The research methods knowledge base. 2nd Edition. Cincinnati, OH. Atomic Dog Publishing.

Willis, J. (2007). Foundations of qualitative research:Interpretative and critical approaches. SAGE Publications,Inc.

Yin,R. (2003). Case study research design and methods.( $3^{\text {rd }}$ edition).London: SAGE Publications.

Yukawa, E. (1997). Language attrition from the psycholinguistic perspective: A literature review. Rapporter om tvåspråkighet. Stockholm, Centre for Research on Bilingualism, Stockholm University: 66. 